\title{
Associations among occupational roles, independence, assistive technology, and purchasing power of individuals with physical disabilities ${ }^{1}$
}

Daniel Marinho Cezar da Cruz ${ }^{2}$

Maria Luisa Guillaumon $\mathrm{Emmel}^{3}$

Objective: to verify whether there are associations among occupational roles, independence to perform Activities of Daily Living, purchasing power, and assistive technology for individuals with physical disabilities. Method: 91 individuals with physical disabilities participated in the study. The instruments used were: Role Checklist, Brazilian Economic Classification Criterion, Barthel Index, and a Questionnaire to characterize the subjects. Results: an association with a greater number of roles was found among more independent individuals using a lower number of technological devices. Higher purchasing power was associated with a lower functional status of dependence. Conclusion: even though technology was not directly associated with independence, the latter was associated with a greater number of occupational roles, which requires reflection upon independence issues when considering the participation in occupational roles. These findings support interdisciplinary actions designed to promote occupational roles in individuals with physical disabilities.

Descriptors: Occupational Therapy; Self-help devices; Activities of Daily Living; Public Policies; Disabled Persons; Role.

\footnotetext{
${ }^{1}$ Paper extracted from Doctoral Dissertation "Papéis ocupacionais e pessoas com deficiências físicas: independência, tecnologia assistiva e poder aquisitivo", presented to Universidade Federal de São Carlos, São Carlos, SP, Brazil.

2 PhD, Adjunct Professor, Departamento de Terapia Ocupacional, Universidade Federal de São Carlos, São Carlos, SP, Brazil.

${ }^{3}$ PhD, Associate Professor, Departamento de Terapia Ocupacional, Universidade Federal de São Carlos, São Carlos, SP, Brazil.
} 


\section{Introduction}

According to the Brazilian Census 2000, about $14.5 \%$ of inhabitants were considered to have at least one type of disability ${ }^{(1)}$. This survey also indicated there is a relationship among disability, poverty and social inequality, showing that $46 \%$ of the disabled individuals with a greater degree of incapacity and $29 \%$ of the disabled individuals with mild and moderate degrees of incapacity live in situations of poverty ${ }^{(1)}$.

The state of São Paulo alone hosts 4.2 million people with disabilities out of the 25 million in the country(2). It is estimated that there are 22,400 people with some type of disability in the city of São Carlos, SP, Brazil(3). The socio-demographic and health indicators for 2009 in Brazil show that the rates of functional incapacity in the poorer elderly (up to one times the minimum wage per capita) are higher than among elderly individuals with higher incomes (more than five times the minimum wage per capita). Hence, data indicate that income is inversely associated with functional capacity, that is, the higher the income, the lower one's functional incapacity ${ }^{(4)}$.

The fact that the association of poverty with functional incapacity to perform Activities of Daily Living (ADLs) tends to grow with the increase of the population of seniors in Brazil is alarming. The 2000 Census shows that the share of the population 65 years old or older has increased in relation to the total Brazilian population: $4.8 \%$ in $1991 ; 5.9 \%$ in 2000 ; reaching $7.4 \%$ in $2010^{(5)}$. Disability is seen both as a cause and a consequence of poverty ${ }^{(6)}$. Around $82 \%$ of people with disabilities worldwide live below the poverty line, mainly children and young individuals; malnutrition is aggravated by problems such as poor education, poor access to information, and limited work opportunities, all of which, are important occupational roles ${ }^{(6)}$.

The recent World Report on Disability 2011, by the World Health Organization jointly with the World Bank, reveals that about $15 \%$ of the world population, that is, more than one billion people, have some type of disability; $20 \%$ of these face great difficulties in daily life. The special needs of people are a concern worldwide given the projection that such needs will increase in the next decades ${ }^{(7)}$. In Brazil, the IBGE published the preliminary results of the Demographic Census 2010 related to disabilities in November 2011. Considering the entire population identified in 2010, 190,755,799 inhabitants (100.0\%), 45,623,910 (23.9\%) individuals have at least one of the investigated disabilities; $145,084,578(76.1 \%)$ have none of these disabilities ${ }^{(3)}$.
In August 25th 2009, Luís Inácio Lula da Silva, president of Brazil at the time, approved, through Decree 6949 Art. $3^{\text {rd }}$, the Convention on the Rights of Persons with Disabilities and its Optional Protocol, signed in New York, USA, on March 30th 2007, ensuring the full implementation and enforcement of its content ${ }^{(8)}$. It is apparent that Brazil, and the world, acknowledges the importance of investing in assistive technology as part of the process of ensuring the rights of these people. The decree highlights technology as a way to ensure fulfilling the commitment to enable people with disabilities to participate in society ${ }^{(8)}$. This participation can occur based on occupational roles, which are considered a set of behaviors expected by society, modeled by culture and that can guide the choice of occupations ${ }^{(9)}$.

The Federal Government defined the term "assistive technology" as synonymous with technical aid, conceptualizing it as field of knowledge, with interdisciplinary characteristics that encompass products, resources, methodologies, strategies, practices and services to promote functionality, activities and the participation of people with disabilities or with impaired mobility. Its purpose is to promote autonomy, independence, quality of life and social inclusion ${ }^{(10)}$. Assistive technology, when appropriate to users and to their environment, has globally been considered to be a powerful tool to encourage independence and social participation $^{(7)}$.

The results reported by a Brazilian pioneer study concerning the occupational roles of caregivers of victims of Traumatic Brain Injury are shown to have adverse repercussions on the social roles of family caregivers, changing or even interrupting the roles performed by caregivers $^{(11)}$. In practical terms, the assessment of occupational roles has also been indicated in a recent study as a strategy to plan interventions and promote environments more conducive to the creation of possibilities to recover lost roles ${ }^{(12)}$.

Considering the previous discussion, this study makes a relevant contribution to the study of existing occupational roles as it investigates whether there is an association among occupational roles with the independence to perform ADLs, exercise purchasing power, and utilize assistive technology, among individuals with physical disabilities. The hypothesis was that these variables would be associated with occupational roles. Even though such a hypothesis has not been previously investigated in the literature, we believe it is relevant for the Brazilian population because it associates not only disability and independence but also personal factors 
(e.g., socioeconomic conditions) together with products and technology.

Poverty that results from a deprivation of occupational roles, those related to education and work among them, may result in a reduced capacity to acquire goods and services, e.g. access to health services, leisure, and diverse types of technology.

This paper presents a discussion concerning physical disability, public policies and occupational roles, which are elements essential to the debate about inclusion in its broader sense, contributing to the discussion of such issues in Brazil. Considering the idea of occupational role as a social representation of individuals is also a way to recognize the importance for individuals with disabilities of participating in school, work, and leisure, among other activities, which are elements that go beyond rehabilitation and seeks independence.

\section{Method}

This is a cross-sectional study of association with a quantitative approach. A convenience sample, composed of individuals with specific characteristics appropriate for the study's purpose, was used(13). The inclusion criteria were: individuals with physical disabilities living in São Carlos, SP, Brazil; enrolled in Family Health Care Units; aged 18 years old or older; able to verbally respond the instruments. Exclusion criteria were: not being cognitively able to answer the data collection instruments and/or having comprehension problems, problems expressing him/herself, or other speaking disorders, since the participants were required to provide verbal answers. A total of 91 individuals with physical disabilities who met these criteria participated in the study.

The following instruments were used to collect data:

1) Role Checklist: This is a semi-structured instrument with a standardized script of American origin(14), validated in Brazil in 2005(15). This type of instrument gives a voice to the respondent, characterizing life aspects and desires $^{(16)}$. Part I of the instrument assesses, through a continuous timeline, the main occupational roles played in the past, present and to be played in the future(14). The instrument presents ten occupational roles: student, worker, volunteer, caregiver, homemaker, friend, family member, religious, amateur, and member of organizations. Part II identifies the degree of importance individuals attribute to each role reported in Part $\mathrm{I}^{(\mathbf{1 4})}$.

2) Brazilian Economic Classification Criterion (CCEB): per capita family income was the indicator of socioeconomic status used. The use of such an indicator is justified since the absence or lack of support (e.g. education, appropriate supply of health services, housing, transportation) plays an important role in the acquisition of goods and services, necessary for social reproduction $^{(17)}$. The CCEB uses a regression analysis of family income based on the possession of goods and education $^{(18)}$. The levels of average family income are distributed according to classes: A1 - R\$11,480.00; A2 - R\$ 8,295.00; B1 - R\$ 4,754.00; B2 - R\$ 2,656.00; C1 - R\$ 1,459.00; C2- R\$ 962.00; D - R\$ 680.00 and E - R\$ 415.00. The scores that classify individuals in each class are: 42 to 46 points are required to be classified in $A 1$; 35 to 41 points for $A 2 ; 29$ to 34 points to be classified in $\mathrm{B} 1 ; 23$ to 28 points for $\mathrm{B} 2 ; 18$ to 22 points for $\mathrm{C} 1 ; 14$ to 17 points for $\mathrm{C} 2 ; 8$ to 13 points for $\mathrm{D}$; and 0 to 7 points are required to be classified in Class $\mathrm{E}$.

3) Questionnaire: Aiming to characterize the individuals in socio-demographic terms in relation to rehabilitation and quantity of assistive technology devices, we deemed that the development of an instrument to describe these aspects was the most appropriate. Questionnaires are frequently used is research to collect information ${ }^{(19)}$.

4) Barthel Index (BI): The BI is an instrument used worldwide to assess functional independence and mobility ${ }^{(20)}$. It determines one's degree of independence in 10 categories: Grooming, Bathing, Feeding, Toilet use, Stairs, Dressing, Bladder, Bowels, Mobility, and Transfer. The validation of BI in Brazil was performed with a population of seniors(20). The sum of its scores enables the following classification: 100 points indicate the individual is totally independent; from 99 to 76 points indicate mild dependence; from 75 to 51 points indicates moderate dependence; from 50 to 26 points indicate severe dependence; and 25 points or less indicate total dependence(21).

Data were collected at the subject's homes using printed instruments. The Role Checklist is a self-reported instrument, but given the characteristics of the target population, illiteracy and/or poor comprehension, we adopted the same procedure used in a previous study ${ }^{(22)}$, which consisted of reading the instrument's questions for the participants in order to ease their understanding.

The Questionnaire contained a list of 16 items addressing assistive technology. Each item was scored 1 point: the minimum score was 0 points, indicating the individual had no resources, and the maximum score was 16 points, indicating the individual had all the devices listed. 
In regard to the $C C E B$, the subjects were classified in classes A1, A2, B1, B2, C1, C2, D and E, according to average income and criteria defined in 2009 and kept up to $2011^{(18)}$.

To analyze data obtained by the Role Checklist, the number of roles was scored from 0 to 10 (Part I) concerning perceived incumbency ${ }^{(23)}$.

For data obtained through BI, the scale's score, which ranges from 0-100 (with intervals of 5 points), were used. In order to consider only categorical variables, we used the classification presented for each category in the $\mathrm{BI}$ and the classification provided by the CCEB.

The incomes recorded on the Questionnaire were categorized as 'times the minimum wage' (i.e. 1, 2, 3,4 or more times the minimum wage); in regard to the number of occupational roles, only those roles the individual play at the present were presented (i.e. 0 to 2, from 3 to 4, 5 or more); the number of technological devices was recorded according to the quantity reported by the participants (i.e. $0,1,2,3$ or more); age was distributed into three groups (up to 50 years old, from 51 to 70 years old, and over 70 years old); and length of injury was also distributed into three groups: up to 4 years; between 4 and 10 years; and over 10 years.

Multiple Correspondence Analysis is a method frequently used in studies assessing associations among categorical variables. The reason is that it enables one to observe concomitantly all information contained in a contingence table, graphically representing the structure of correlations, which would not be possible if analysis was done in pairs. Graphical observation for this type of analysis should attend to the fact that each point relates to a category of a certain question; categories near by are more correlated with each other than they are with distant categories. In practice, if two categories concerning different questions are close within the graph, it means that those who chose one of the options also chose the other. It is worth noting that the existence of categories with a low frequency hinders the analysis. Hence, categories are often gathered together to allow for a more consistent observation of how data behave. Analyses were performed through the Statistical System (SAS), Statistical Package for the Social Sciences (SPSS), and Microsoft Excel.

The study was submitted to and approved by the Institutional Review Board at the Federal University of São Carlos (UFSCar) (Process No. 392/2011, CAAE 0079.0.135.000-11). All the subjects signed free and informed consent forms.

\section{Results}

The 91 participants were distributed into 46 men and 45 women. The average age was 62.2 years old, median was 65 years old and standard deviation was 18.4 years. Length of disability was 10.3 years, with a standard deviation of 13.32 years. The individuals' diagnoses included: Stroke, Peripheral Upper Limb Injury, Polio, Neuromuscular Disorders, Traumatic Brain Injury, Cerebral Palsy, Spinal Cord Injury, Amputation of Upper Limb, Parkinson's Disease, Brachial Plexus Injury, Myelomeningocele, Huntington's chorea, Stikler Syndrome, and unspecified degenerative disease.

The most frequently reported assistive resources among the $100 \%(n=199)$ identified in the studied sample were those to assist mobility with $46 \%(n=92)$, to assist ADLs with $29 \%(n=58)$, followed by Prosthetics and Orthotics with $10 \% \quad(n=20)$, Environmental Accessibility with $9 \%(n=18)$, and devices to promote Proper Positioning with $6 \%(n=11)$. In regard to level of independence, the results obtained by the BI revealed that the classification of mild dependency was predominant among the subjects (Table 1 ).

Table 1 - Classification of independence/dependence in the studied sample $(n=91)$. São Carlos, SP, Brazil, 2011

\begin{tabular}{lcc}
\hline \multicolumn{1}{c}{ Barthel Index's classification } & Frequency & Percentage \\
\hline Mild dependence & 55 & 60.4 \\
Moderate dependence & 14 & 15.4 \\
Severe dependence & 10 & 11.0 \\
Total dependence & 5 & 5.5 \\
Total independence & 7 & 7.7 \\
\hline
\end{tabular}

In regard to purchasing power, measured through the CCEB, most of the sample was classified as B2 and C1 as shown in Table 2.

Table 2 - Distribution of the sample $(n=91)$ into economic classes according to purchasing power. São Carlos, SP, Brazil, 2011

\begin{tabular}{ccc}
\hline Purchasing power - Economic classes & Frequency & Percentage \\
\hline B2 & 33 & 36.3 \\
C1 & 20 & 22.0 \\
B1 & 13 & 14.3 \\
C2 & 12 & 13.2 \\
D & 11 & 12.1 \\
A2 & 2 & 2.2 \\
\hline
\end{tabular}


In relation to the number of occupational roles, a predominance of three to four roles was identified, as shown in Table 3.

Table 3 - Frequency of occupational roles played in the present as reported by the sample $(n=91)$. São Carlos, SP, Brazil, 2011

\begin{tabular}{ccc}
\hline $\begin{array}{c}\text { Number of Occupational Roles in } \\
\text { the present }\end{array}$ & Frequency & Percentage \\
\hline 3 to 4 & 42 & 46.2 \\
0 to 2 & 30 & 33.0 \\
5 or more & 19 & 20.9 \\
\hline
\end{tabular}

As for the quantity of technological resources, the individuals were well distributed, while the possession of three devices obtained the highest percentage, $35.2 \%$ $(n=32)$, followed by the possession of one device, $29.7 \%$ $(n=27)$; the possession of two devices, $22 \%(n=20)$; and $13 \%(n=12)$ reporting no device.

The results of the Correspondence Analysis for independence, income, number of occupational roles, purchasing power, age and length of injury are presented in Figure 1.

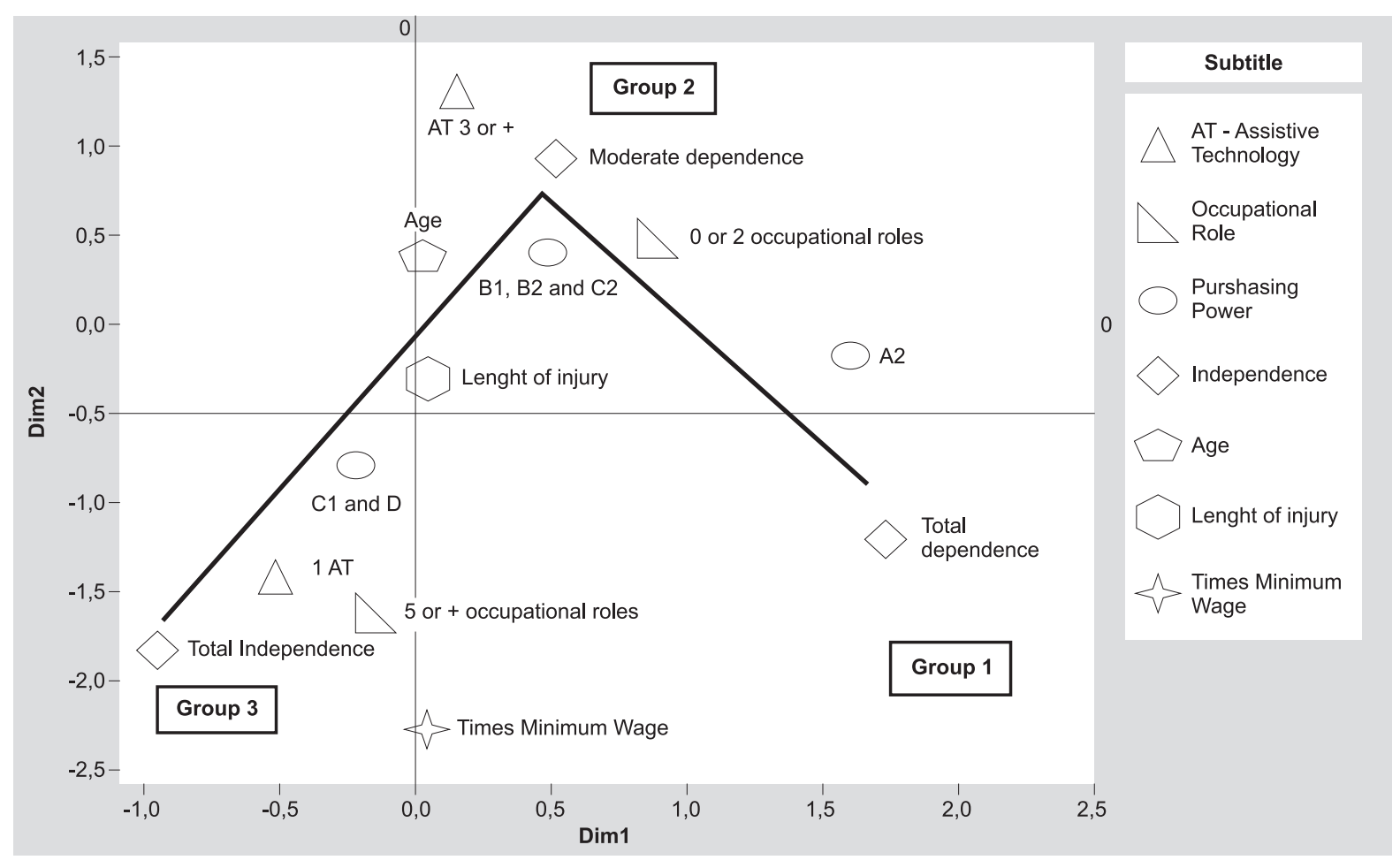

Figure 1 - Representation of the Correspondence Analysis ( $n=91)$. São Carlos, SP, Brazil, 2011

The trend found is represented in Figure 1 with the formation of three groups of association. The sample is distributed in relation to the individuals' dependence. The BI's total classification shows this trend followed an order of total dependence (Group 1) to moderate dependence (Group 2) to total independence (Group 3). The Role Checklist shows that the most independent individuals (Group 3) were those who presented a greater number of occupational roles (5 or more) and only one technological resource, thus, showing there is an association between individuals with a greater number of occupational roles and a greater independence to perform ADLs.
In regard to assistive technology, the greater the independence, the lower the number of technological devices used. The individuals with moderate dependence had three or more technological devices and from 0 to 2 occupational roles (Group 2), while those who were totally dependent were not associated with technology or with occupational roles (Group 1). An analysis of the CCEB's classification, which measured purchasing power, shows that Classes D and $\mathrm{C} 1$ were more associated with lower dependence (Group 3), while Classes B1, B2 and C2 were associated with moderate dependence (Group 2); Class A2, though it appears less frequently and with little explanation justifying its result, was associated 
with total dependence (Group 1). Both the individuals' age and length of injury, together with income, were not associated with any of the remaining categories, appearing in the center of the graphic.

\section{Discussion}

In regard to assistive technology, a predominance of mobility aids was observed, especially canes. It may be explained, at least in part, by the fact that the sample was predominantly composed of seniors, with diagnoses and impairment resulting in musculoskeletal changes. These results are similar to those reported by a study that identified 76 devices in use by community seniors; $59.2 \%(n=45)$ of these were mobility aids, mainly canes, $44.73 \%(n=34)^{(24)}$.

The fact that, in general, this study's individuals did not present severe dependence does not exclude the possibility of them using technology. The use of technology could promote increased independence in many of the cases, while an absence of technology might have led to greater dependence. Consequently, when considering technologies to promote occupational performance, we deemed it important to investigate the potential relationship with such resources. The results, however, were contrary to what we expected, that is, the number of technological devices was lower for those with greater independence. The classes with a lower amount of technological resources were associated with the classes of independent individuals, while those with some degree of dependence used a larger number of technological devices.

The initial hypothesis was that individuals with a greater number of technological devices would be more independent given the use of such resources. There are various explanations for these results and we highlight some: a) the devices are not being used; b) the devices may not assist the issues related to independence investigated in this study; c) technology can assist in some, but not in all, of the individuals' activities; d) culturally, the relationship of dependence of individuals on their families and the characteristics inherent to the aging process itself, may influence both functionality and the use of technology.

Based on these results, we can reflect upon the relative role technology plays in the lives of individuals with disabilities. When technology is prescribed, monitored and appropriate to the individual's context and needs, it can be an important resource that contributes to functionality. Such functionality, however, does not replace technology, but helps in the performance of certain functions.

In this context, in regard to the Family Health Strategy, we note the importance of cooperation being established between Family Health Care Units and Family Health Support Centers so that these services can appropriately monitor and refer individuals with disabilities to specialized care and encourage improved organization and functioning of health care services and multidisciplinary teams in relation to the acquisition of technologies that enable these people to play occupational roles.

Additionally, when analyzing the classification obtained through the CCEB, which measured purchasing power, we note a tendency of classes with a lower purchasing power to be more associated with lower dependence, while the opposite was observed among higher economic classes. Functional status results from diverse special situations with a multifactor origin associated with changes arising from a normal aging process, from chronic and impairing pathologies, sedentariness, and often unfavorable socioeconomic situations(24). Nonetheless, functional status, related to purchasing power in this study, showed an unexpected relationship, different from what is reported in the literature: individuals with lower purchasing power were the most independent individuals.

These results differ from an IBGE study based on socio-demographic and health indicators found in Brazil in 2009: the rates of functional impairment in a sample of poor seniors (up to one times the minimum wage per capita) were above those found among individuals with higher incomes ${ }^{(4)}$.

This result, however, should be qualified, since the frequency of individuals with higher purchasing power, those classified in higher classes (e.g. A2), was low. Hence, further research investigating these findings in broader samples, is suggested in order to compare results. We do not discard the hypothesis that such findings were unusual due to the socioeconomic criterion used in this study- purchasing power instead of per capita income. Quantitative studies conducted in developing countries and adopting the socioeconomic status of individuals with disabilities suggest that these people are at a disadvantage in relation to education and employment, but evidence is not conclusive for assigning a poverty status based on purchasing power, income or consumption expenditure ${ }^{(7)}$.

There are some potential explanations to be presented in the discussion of this study's results. Clinical experience has shown that, in fact, individuals with higher purchasing 
power present lower level of independence, even when their capacity could reflect greater independence. Analyses of these aspects have often taken into account factors that involve passivity and overprotection, the convenience of having a caregiver perform activities for them, easy access to technologies, and the belief that corrective/restorative rehabilitation will rapidly and easily enable independence. These findings also allow a discussion concerning capacity (what individuals are really capable of) and the issue of performance (what they actually do within their particular context of life).

Perhaps, what we observe in clinical practice in relation to individuals with lower purchasing power is due to reasons contrary to the ones previously discussed. Because resources are scarce, these individuals adapt their environmental needs to what they have available in their context. They seek independence adaptation, at the same time, to their real conditions of life. Even though there are no studies focusing on the association of independence with the occupational roles of individuals with physical disabilities, there are studies correlating the performance of roles with greater satisfaction in life in a sample of seniors ${ }^{(23)}$.

A pioneer Brazilian study addressing occupational roles highlights the scarcity of studies conducted with disabled individuals(11). Therefore, the contribution and continuity of investigations addressing these issues in the Brazilian population, where social inequalities are persistent, is very relevant. It is important to consider how to enable individuals to recover occupational roles or even acquire new ones, identifying their performance capacity, skills, and strengths present in the environment, and which these individuals require to perform desired roles, and finally, how the actions of different health workers could promote such roles.

In summary, the fact that not all the studied variables were associated, namely independence, purchasing power, occupational roles, and number of technological devices, reflect, to a certain extent, nonlinearity among these variables, due to the complexity that surrounds them. In this sense, one needs to reflect upon the interaction among environmental influences, the human being, and his/her occupations when thinking about the participation of occupational roles and the technology mediating such participation.

\section{Conclusion}

Even though, we believe this study met its objectives, there are some limitations to note. Because the study's design includes a convenience sample, the results may not be generalized to the population with physical disabilities in the city of São Carlos, SP, Brazil; these findings are restricted to the studied sample.

These results show the existence of associations among some variables, but not all those included in this study. It is worth noting that, even though technology was not directly associated with independence, the latter was associated with a greater number of occupational roles. Such a result requires one to consider independence issues when looking at participation in occupational roles and how independence mediates these individuals' roles in daily life. Further studies are relevant that address the effects of interventions designed to change the occupational roles of individuals with physical disabilities and also, whenever possible, to broaden occupational roles, even among individuals with low independence in the performance of ADLs. The development of multidisciplinary strategies, focused on individuals with physical disabilities and their needs, desires, and abilities with the purpose to encourage real social inclusion, are pertinent given the typological complexity of the different occupational roles.

\section{References}

1. Neri M, Pinto A, Soares W, Costilla H. Retratos da Deficiência no Brasil. Rio de Janeiro: FGV/IBRE, CPS; 2003. 200 p.

2. Battistella LR. O prefeito cidadão. In: Fundação prefeito Faria Lima-Cepam; Secretaria dos direitos da pessoa com deficiência. Política municipal dos direitos da pessoa com deficiência. São Paulo; 2009. p. 5-5.

3. Instituto Brasileiro de Geografia e Estatística (IBGE). Sinopse do Censo demográfico 2010. [acesso 15 jun 2011]. Disponível em: http://www.ibge.gov.br/home/ estatistica/populacao/censo2010/sinopse.pdf

4. Instituto Brasileiro de Geografia e Estatística (IBGE). Indicadores sociodemográficos e de saúde no Brasil 2009. [acesso 12 jun 2011]. Disponível em: http:// www.ibge.gov.br/home/estatistica/populacao/indic sociosaude/2009/default.shm

5. Instituto Brasileiro de Geografia e Estatística (IBGE). Censo Demográfico: Resultados preliminares da amostra 2010. [acesso 20 nov 2011]. Disponível em: http://www.ibge.gov.br/home/estatistica/populacao/ censo2010/resultados_preliminaresamostra/default_ resultados_preliminares_amostra.shtm

6. Instituto de Tecnologia Social (ITS). Conhecimento: pontes para a vida 2007. [acesso 1 jan 2011]. Disponível em: http://www.itsbrasil.org.br/publicacoes 
7. World Health Organization (WHO). World Report on Disability 2011. [acesso em12 jun 2011]. Disponível em: www.who.int

8. Decreto 6949, de 25 de agosto de 2009 (BR). Promulga a Convenção Internacional sobre os Direitos das Pessoas com Deficiência e seu Protocolo Facultativo, assinados em Nova York, em 30 de março de 2007. [acesso 1 out 2009]. Disponível em: http://www.planalto.gov.br/ ccivil_03/_ato2007-2010/2009/decreto/d6949.htm

9. American Occupational Therapy Association - AOTA. Occupational therapy practice framework: domain and process (2nd). Am J Occup Ther. 2008;625-83.

10. Ata VII de constituição do Comitê de Ajudas Técnicas (CAT). [acesso 26 nov 2009]. Disponível em: http:// www.mj.gov.br/sedh/ct/corde/dpdh/corde/comiteat.asp 11. Serna ECH, Sousa RMC. Mudanças nos papéis sociais: uma conseqüência do trauma crânio-encefálico para o cuidador familiar. Rev. Latino-Am. Enfermagem. 2006;14(2):183-9.

12. Quiles-Cestari LM, Ribeiro RPP. Os papéis ocupacionais de mulheres com anorexia nervosa. Rev. Latino-Am. Enfermagem. [periódico na Internet]. mar-abr 2012 [acesso 1 nov 2012]; 20(2):[08 telas]. Disponível em: http://dx.doi.org/10.1590/S0104-11692012000200004 13. Cozby PC. Métodos de pesquisa em ciências do comportamento. São Paulo: Atlas; 2003. 456 p.

14. Oakley F, Kielhofner G, Barris R, Reichler RK. The role checklist: development and empirical assessment of reliability. Occup Ther J Res. 1986;6(3):157-70.

15. Cordeiro JJR, Camelier A, Oakley F, Jardim MJR. Cross-cultural reproducibility of the Brazilian portuguese version of the role checklist for persons with chronic obstructive pulmonary disease. Am J Occup Ther. 2007;61(1):33-40.

16. Kielhofner G, Forsyth K, Suman M, Kramer J, Thomas-Nakamura H.; Yamada T, et al. A. Self-reports: eliciting client's perspectives. In: Kielhofner G. Model of Human Occupation: theory and application. 4th.ed. Baltimore: Lippincott Williams \& Wilkins; 2008. p. 237261.

17. Parahyba MI, Stevens K, Henley W, Lang IA, Melzer $D$. Reductions in disability prevalence among the highest income groups of older Brazilians. Am J Public Health. 2009;99(1):81-6.

18. Associação Brasileira de Empresas de Pesquisa (ABEP). [acesso 18 mar 2011]. Disponível em: http:// www.abep.org/
19. Barros AJP, Lehfeld NAS. Projeto de pesquisa: propostas metodológicas. 13.ed. Petrópolis: Vozes; 2002. $127 \mathrm{p}$.

20. Minosso JSM, Amendola F, Alvarenga MRM, Oliveira MAC. Validação, no Brasil, do Índice de Barthel em idosos atendidos em ambulatórios. Acta Paul Enferm. 2010;23(2):218-23.

21. Araújo F, Ribeiro JLP, Oliveira A, Pinto C. Validação do Índice de Barthel numa amostra de idosos não institucionalizados. Rev Port Saúde Pública. 2007;25(2):59-66.

22. Hallet JD, Zasler PM, Maurer P, Cash S. Role change after traumatic brain injury in adults. Am J Occup Ther. 1994;48(3):241-6.

23. Elliot MS, Barris R. Occupational role performance and life satisfaction in elderly persons. Occup Ther J Res. 1987;7(4):215-24.

24. Mello MAF. A necessidade de equipamentos de auto-ajuda e adaptações ambientais de pessoas idosas dependentes vivendo na comunidade em São Paulo, Brasil [tese de doutorado]. São Paulo (SP). Programa de Reabilitação da Escola Paulista de Medicina da Universidade Federal de São Paulo; 1999. 91 p. 